\title{
EXPRESSION OF SECRETED FRIZZLED-RELATED PROTEIN 2 IN A PRIMARY CANINE MAMMARY TUMOR CELL LINE: A CANDIDATE TUMOR MARKER FOR MAMMARY TUMOR CELLS
}

\author{
JIA-LIN LEE, CHING-JIN CHANG, LING-LING CHUEH, AND CHUNG-TIEN LIN' \\ Graduate Institute of Veterinary Medicine, National Taiwan University, Taipei 106, Taiwan, Republic of Chinca (J.-L. L., L.-L. C., C.-T. L.) \\ and Institute of Biological Chemistry, Academia Sinica, Taipei 115, Taiwan, Republic of Chinca (C.-J. C.)
}

(Received 21 April 2003; accepted 15 July 2003)

\begin{abstract}
SUMmaRY
Canine mammary tumors (CMTs) have been proposed to be a good animal model for human breast cancer. To provide a basis for the tumorigenic study of CMTs, cell lines were established using a modified cell culture technique. The epithelial morphology and immunostaining with cytokeratin 18 confirmed the epithelial origin of the cells. In an investigation of possible mammary tumorigenesis-related factors, the expression of Wnt signaling-related proteins was detected in cell lines. Secreted frizzled-related protein 2 (SFRP2) was abundantly expressed in CMT cells but not in normal canine mammary gland (MG) cells. Secreted frizzled-related protein 2 was secreted into the eulture medium and was associated with the extracellular matrix. In addition, increased expressions of $\beta$-catenin and cyclin D1 were observed in cells overexpressing SFRP2. The marked differential expression of SFRP2 reveals that this protein may be a potential candidate marker for CMTs. The CMT cell line established in this study provides a useful tool and experimental model for understanding both the tumorigenesis of CMTs and the role of Wnt signaling in cancers.
\end{abstract}

Key words: mammary gland tumor; SFRP2; Wrt signaling; $\beta$-catenin; cyclin D1; primary culture.

INTRODUCTION

Canine mammary tumors (CMTs) are the most common tumor type in female dogs, comprising $52 \%$ of all neoplasms. They are the canine counterparts of human breast cancer and these cancers share several similar aspects (Nerurkar et al., 1989). During the past three to four decades, CMTs have been proposed as a good animal model for human breast cancer (Schneider, 1970; Strandberg and Goodman, 1974; Chrisp and Spangler, 1980; Pierrepoint, 1985). Mammary neoplasms are important and common tumors in both animals and humans; however, their etiology is poorly understood. Classification of CMTs is mostly based on classic histopathology, which remains subjective (Fowler et al., 1974; Fuentealba and Mullins, 1999). The ability to establish primary cultures of tumor cells is an important prerequisite in cancer research, allowing the study of carcinogenesis, prognostic factors, and therapeutic agents (Hood and Parham, 1998). Methods for establishing primary cell cultures include mechanical disaggregation and enzymatic digestion (Dendy, 1976). Tumors are complex lesions composed of heterogeneous populations of malignant and stromal cells (e.g., the supporting extracellular matrix; ECM), especially in CMTs. Therefore, immunohistochemical evaluation of intermediate filaments is a powerful tool in the population characterization and histogenesis of cells (Grown and Vogel, 1985; Moore et al., 1989; Andreasen et al., 1998). The secreted frizzled-related protein (SFRP) family is

${ }^{1}$ To whom correspondence should be addressed at Department of Veterinary Medicine, National Taiwan University, No. 1 Roosevelt Road, Section 4 Taipei 106, Taiwan, Republic of China. E-mail: ctlin@ccms.ntu.edu.tw implicated as having dual roles in modulation of the Wnt frizzled signal transduction pathway and regulation of apoptosis. Signaling pathways play an important role in development and tumorigenesis (Finch et al., 1997; Melkonyan et al., 1997; Zhou et al., 1998; Schumann et al., 2000). The Wnt signaling pathway is initiated from an interaction of Wnt proteins with receptors, which have been identified as members of the frizzled and SFRP families. After Wnt protein binds to its receptors, a cytoplasmic protein, Disheveled, is phosphorylated, and the activity of GSK3 $\beta$ is suppressed, leading to accumulation of $\beta$-catenin in the nucleus of cells. $\beta$-Catenin then interacts with members of the LEF-1/TCF families of high mobility group (HMG) box transcription factors, thereby contributing to expression of specific target genes (such as cyclin DI and c-Myc) (Huelsken and Birchmeier, 2001).

Secreted frizzled-related proteins comprise a family of secreted molecules that contain an N-terminal cysteine-rich domain (CRD) homologous to the CRDs of the frizzled family of transmembrane Wnt receptors (Finch et al., 1997; Melkonyan et al., 1997). Seven SFRPs have been identified from mammalian tissues to date (Jones and Jomary, 2002). They are implicated as having dual roles in modulation of the Wnt frizzled signal transduction pathway and regulation of apoptosis. Recently, it has been reported that SFRP2 possesses antiapoptotic activity, whereas SFRPI induces proapoptotic activity-apoptosis in a breast cancer cell line (Melkonyan et al., 1997). However, the mechanism and pathway of apoptosis mediated by SFRP2 are completely not known. Canine SFRP2 was first identified from a subtractive canine retinal complementary deoxyribonucleic acid (cDNA) library, and the gene is not abun- 
dantly expressed in most normal canine adult tissues (Lin and Sargan, 2001). In our recent results of screening the expression of SFRP2 in CMT specimens, SFRP2 was found to be abundantly expressed in human MTs and CMTs but was undetectable in normal canine mammary gland (MG) tissues (Lee et al., in prep.). Further characterization of the functions of SFRP2 in CMTs remains to be performed. In this study, we established primary CMT cell lines and characterized the cell lines for the expression of SFRP2, $\beta$-catenin, and cyclin DI.

\section{Materials and Methods}

Primary cultures from mammary tissues. Mammary tissues were collected from freshly excised specimens. Tissues were washed three times in phosphatebuffered saline (PBS) and then cut into about $1-\mathrm{mm}$ pieces. Dulbecco modified Eagle medium (DMEM) (high ghucose, GIBCO BRL, Grand Island, NY), supplemented with 100 units $/ \mathrm{ml}$ penicillin $\mathrm{G}$ and $100 \mu \mathrm{g} / \mathrm{ml}$ streptomycin, was added and shaken violently for $1 \mathrm{~min}$. The medium was centrifuged at $300 \times$ $g$ for $5 \mathrm{~min}$. The supernatant was transferred to another tube, and fresh DMEM was added to the minced tissues. This step was repeated three times. Single cells in the supernatant were pelleted by centrifugation at $1000 \times g$ for 5 min and resuspended using fresh DMEM. The cells were plated in a 25T-flask and incubated at $37^{\circ} \mathrm{C}$ in a humidified atmosphere of $5 \%$ carbon dioxide in air. Above all, every step was performed using mechanical techniques, instead of enzymatic digestion. Culture media supplemented with $10 \%$ fetal calf serum (FCS) (HyClone, Logan, Utah) were changed for the first time after $3-4 \mathrm{~d}$. In the following $\mathrm{d}$, cells were passaged when cells reached $70-80 \%$ confluence.

Agar and dilution cloning. After enrichment of epithelial cells, cells (1.0 $\left.\times 10^{3}\right)$ were layered with $20 \%$ FCS medium containing $0.3 \%(w / v)$ agar. After $1 \mathrm{wk}$, fresh medium was added, and colony formation was determined on day 14. The experiments were performed essentially as described previously (Schleger et al., 1997). After agar cloning, cells $\left(1.0 \times 10^{2}\right)$ of a single colony were plated in 96-well plates (NUNC, Life Technologies, Carlsbad, California). Each well was filled with $1 \mathrm{ml}$ of culture media and a single cell. Cells were incubated at $37^{\circ} \mathrm{C}$. After $6 \mathrm{~h}$, we confirmed by light microscopy that only a single cell was present in one well. Single cells were identified and marked. A few of the single cells proliferated and reached subconfluency after 2-3 wk. Cells were trypsinized and replated in 12-well plates. After four to five passages, 5-10 subpopulations of cells in each CMT specimen were identified.

Proliferation assay. After agar and dilution cloning, cell proliferation was assessed using a standard 3-(4,5-dimethylthiazole-2-yl)-2,5-biphenyl tetrazolium bromide (MTT) assay (Promega, Madison, Wisconsin). Typically, $10^{3}$ cells were plated into each well in 96-well plates. The assay was performed according to the manufacturer's instructions. The premixed, optimized dye solution was added to each well. During a 4-h incubation, the solubilization-stop solution was then added to the culture wells to resolve the formazan product. Relative concentrations of formazan (as indicators of cell number) were determined by quantifying the optical absorbance at $570 \mathrm{~nm}$ using a control wavelength of $690 \mathrm{~nm}$ in an automatic plate reader.

Immunohistochemistry. Immunohistochemistry was carried out using antibodies against cytokeratin 18 (Becton Dickinson, Franklin Lakes, NJ) and SFRP2 (Santa Cruz Biotechnologies, Santa Cruz, California) to analyze the protein distribution in primary CMT and normal MG cells. Cells were fixed by $4 \%$ paraformaldehyde in PBS. Immunolabeling and immunodetection were carried out using the Peroxidase Substrate Kit (Vector Laboratories, Burlingame, California). Color development was performed by incubation using a DAB chromogen solution containing hydrogen peroxide. Cells were counterstained with the nuclear stain, hematoxylin.

Reverse transcriptase-polymerase chain reaction. Ribonucleic acid (RNA) extraction protocols were carried out using homogenized cells with TRIzol (Life Technologies). Approximately I $\mu$ g of total RNA was reverse transcribed in $20-\mu \mathrm{l}$ reactions with $200 \mathrm{U}$ Moloney murine leukemia virus reverse transcriptase (Promega) and Oligo-dT primers (Promega) for $50 \mathrm{~min}$ at $42^{\circ} \mathrm{C}$. Polymerase chain reaction (PCR) amplification was performed using SFRP2 sequence-specific primers ( $\mathrm{Lin}$ and Sargan, 2001) (GenBank accession no. AJ407833): 5'-GAC AAC GAC ATA ATG GAA ACT C-3' and $5^{\prime}$-CAT GCT ATG GTG GTT AAT GTG-3'. For PCR amplification, $0.5 \mu 1$ of the total cDNA was used in $20-\mu \mathrm{l}$ reactions containing $10 \mathrm{pmol}$ of each primer, $10 \times$ PCR buffer $(2 \mu \mathrm{l}), 10 \mathrm{mM}$ deoxynucleoside triphosphates $(0.4 \mu \mathrm{l}), 25 \mathrm{mM}$
$\mathrm{MgCl}_{2}(0.28 \mu \mathrm{l})$, and $5 \mathrm{U}$ Taq DNA polymerase (Promega), with the following conditions: $94^{\circ} \mathrm{C}$ for $3 \mathrm{~min}$; then 35 cycles of $94^{\circ} \mathrm{C}$ for $60 \mathrm{~s}, 60^{\circ} \mathrm{C}$ for $60 \mathrm{~s}$, and $72^{\circ} \mathrm{C}$ for $90 \mathrm{~s}$; and a final step of $72^{\circ} \mathrm{C}$ for $10 \mathrm{~min}$.

In situ RNA hybridization experiments for SFRP2. In situ hybridization of SFRP2 in CMT and normal MG cells was performed using digoxigenin (DIG)labeled SFRP2 complementary RNA (cRNA) probes. Digoxigenin-labeled RNA corresponding to sense and antisense probes was prepared from canine retinal SFRP2 cDNA in pBluescript (Lin and Sargan, 2001) by in vitro transcription using T7 or T3 polymerases according to the manufacturer's instructions (DIG RNA Labeling Kit, Boehringer Mannheim, Mannheim, Germany). The DIG-labeled SFRP2 cRNA probe at $1 \mathrm{mg} / \mathrm{ml}$ was added to freshly prepared hybridization mixture and applied to the tissue sections for $24 \mathrm{~h}$ at $42^{\circ} \mathrm{C}$. Anti-DIG-alkaline phosphatase (Fab fragments) was added, and color developmem was performed in a solution containing nitroblue tetrazolium and 5-bromo-4-chloro-3-indolyl-phosphate. Sections were counterstained with the nuclear stain, methyl green.

Protein preparation and immunoblotting. Cells were grown to approximately 80\% confluence, washed with PBS, and scraped into $100 \mu$ lysis buffer. Media from the cell cultures were concentrated by centrifuging at $7500 \times g$ for $15 \mathrm{~min}$ using Vivaspin6 concentrators (VIVA Science, Hannover, Germany). For experiments on the ECM, the ECM fraction was prepared essentially as described previously (Bafico et al., 1999). In brief, cultures were washed twice with PBS containing $1 \mathrm{mg} / \mathrm{ml}$ aminocaproic acid and $1 \mathrm{~m} M$ phenylmethylsulfonyl fluoride and then incubated with the same solution containing $5 \mathrm{mM}$ ethylene glycol-bis(aminoethylether)-tetraacetic acid for $15 \mathrm{~min}$ at $37^{\circ} \mathrm{C}$. Cells were removed, and plates were washed two to three times with the PBS and then twice with distilled water. The ECM was then dissolved in $200 \mu \mathrm{l}$ of Laemmli buffer. Other fractions of cells were prepared as described previously (Lin et al, 2002). Details of immunoblotting were essentially as previously described (Chang et al., 1998). The protein concentration of each sample was determined using a protein assay kit (BioRad Laboratories, Kowloon, Hong Kong). An equal amount of protein was resolved by sodium dodecyl sulfate-polyacrylamide gel electrophoresis and analyzed by immunoblotting with rabbit polyclonal antibodies against SFRP2 (Santa Cruz Biotechnologies), mouse monoclonal antibodies against cytokeratin 18 and $\beta$-catenin (Santa Cruz Biotechnologies), and mouse monoclonal antibodies against cyclin D1 (NeoMarkers, Fremont, California) using the Amersham Pharmacia Biotech, Freiburg, Germany chemiluminescence system for staining detection.

\section{RESULTS}

Primary culture of mammary tissues. All colonies of CMT (e.g., MPG 1-4) cells were kept in culture up to the 70th passage; normal MG (e.g., NMG1-2) cells were kept in culture up to the 10th passage. Cells showed mixed types initially, containing polygonal and cuboidal epithelial cells, stellate myoepithelial cells, and stem cells. Approximately 10-20\% of cells showed fibroblastic, spindleshaped morphology (Fig. 1, upper). Mitotic figures were occasionally visible. Agar and dilution cloning was performed to purify the cell cultures and to rule out fibroblast contamination. After purification, $>90 \%$ of cells exhibited the same phenotype based on morphology (Fig. 1, bottom).

Confirmation of the epithelial origin of cultured cells. The cytokeratin of intermediate filaments was detected immunohistochemically to confirm the epithelial origin of the cultured cells. Cells of the primary culture (alveolar and ductal epithelial cells) were positive for cytokeratin 18, which precluded the possibility of their being fibroblasts. All colonies of primary cultures were positive for cytokeratin 18 by Western blotting (Fig. $1 B$ ). In addition, immunoreactivity was intracytoplasmic, predominantly located at the apical portion of the cytoplasm (Fig. $1 C$, upper). Furthermore, we tried to determine the cytokeratin expression of the cultured cells in the original tissues. Cytokeratin was also detected immunohistochemically on paraffin-embedded mammary tissue sections. Alveolar and 

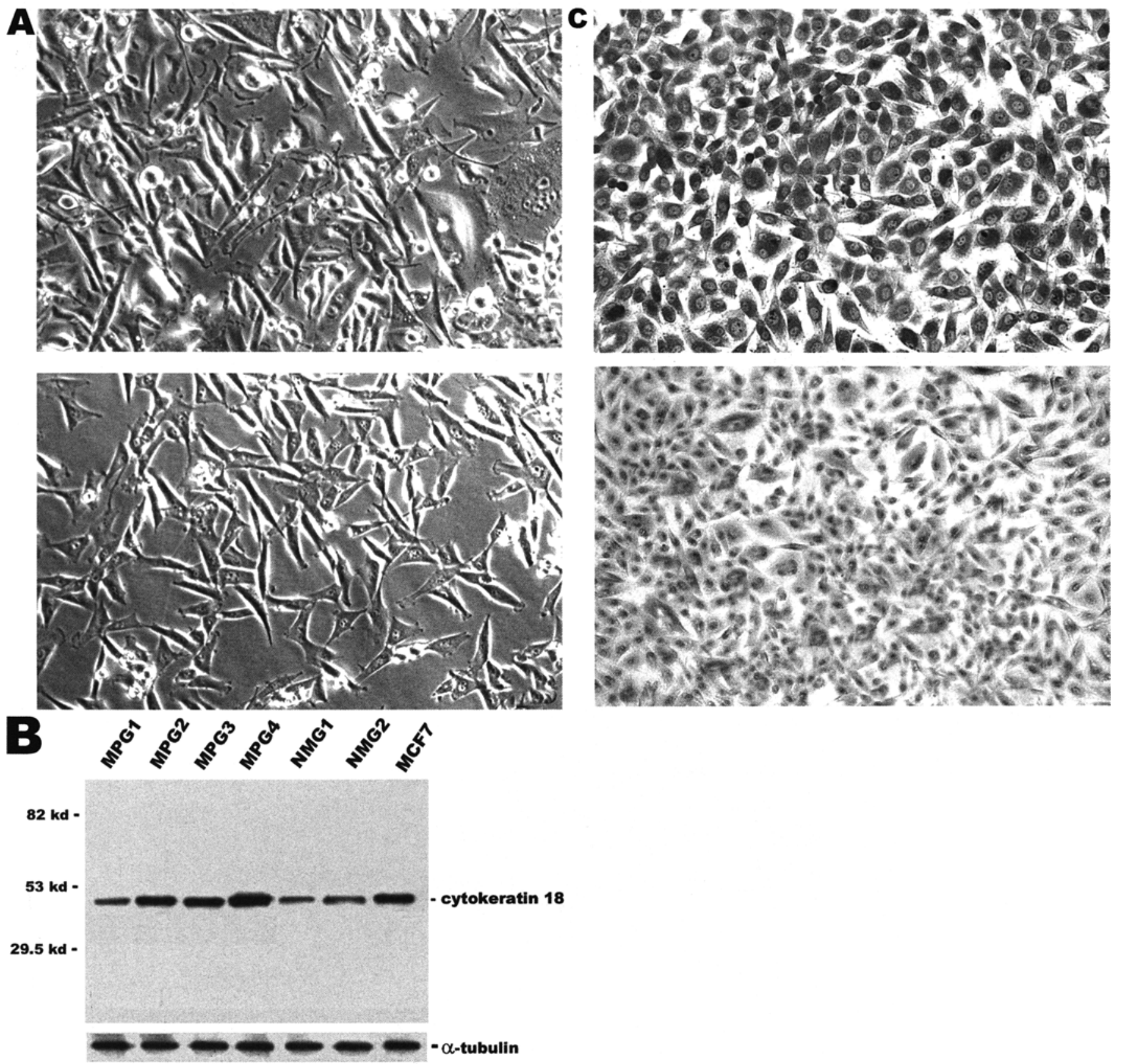

FIG. 1. Primary culture from mammary tissues. $(A$, upper $)$ Mixed cell types of primary culture from CMTs. $(A$, bottom) Primary culture after purification by agar and dilution cloning. $(B)$ Cytokeratin 18 was detected in all colonies of primary cultures by Western blotting. MCF7 served as a positive control. The expected size of the cytokeratin 18 protein was $45 \mathrm{kDa}$. (C) Cytokeratin 18 was detected immunohistochemically in MPGI to prove the epithelial origin of cultured cells. Bottom: negative control. CeIls were counterstained with the nuclear stain, hematoxylin. Magnification: $\times 200$. CMTs, canine mammary tumors; MPG, primary culture from CMTs; NMG, primary culture from normal canine mammary glands.

ductal epithelial cells of paraffin-embedded mammary tissue sections were positive for cytokeratin 18 (data not shown).

Characterization of MPG and NMG cells. To characterize differences between MPG and NMG cells, colony-forming efficiency was determined, and an MTT assay was performed. Colony-forming efficiency of MPG cells was significantly higher than that of NMG cells (Fig. 2A). In previous studies, growth of nontumor epithelial and endothelial cells was strictly anchorage dependent, with strong cell-matrix and cell-cell contacts (Frisch and Francis, 1994). When cultured in suspension, cells rapidly undergo apoptosis in a process termed anoikis (Frisch and Francis, 1994). In addition, the proliferation rate of MPG cells was also higher than that of NMG cells according to the MTT assay (Fig. 2B). Therefore, we suggest that MPG cells are tumorous and not normal epithelial cells.

Messenger ribonucleic acid analysis of canine SFRP2. The photograph in Fig. $3 A$ shows the analysis for SFRP2 expression in 

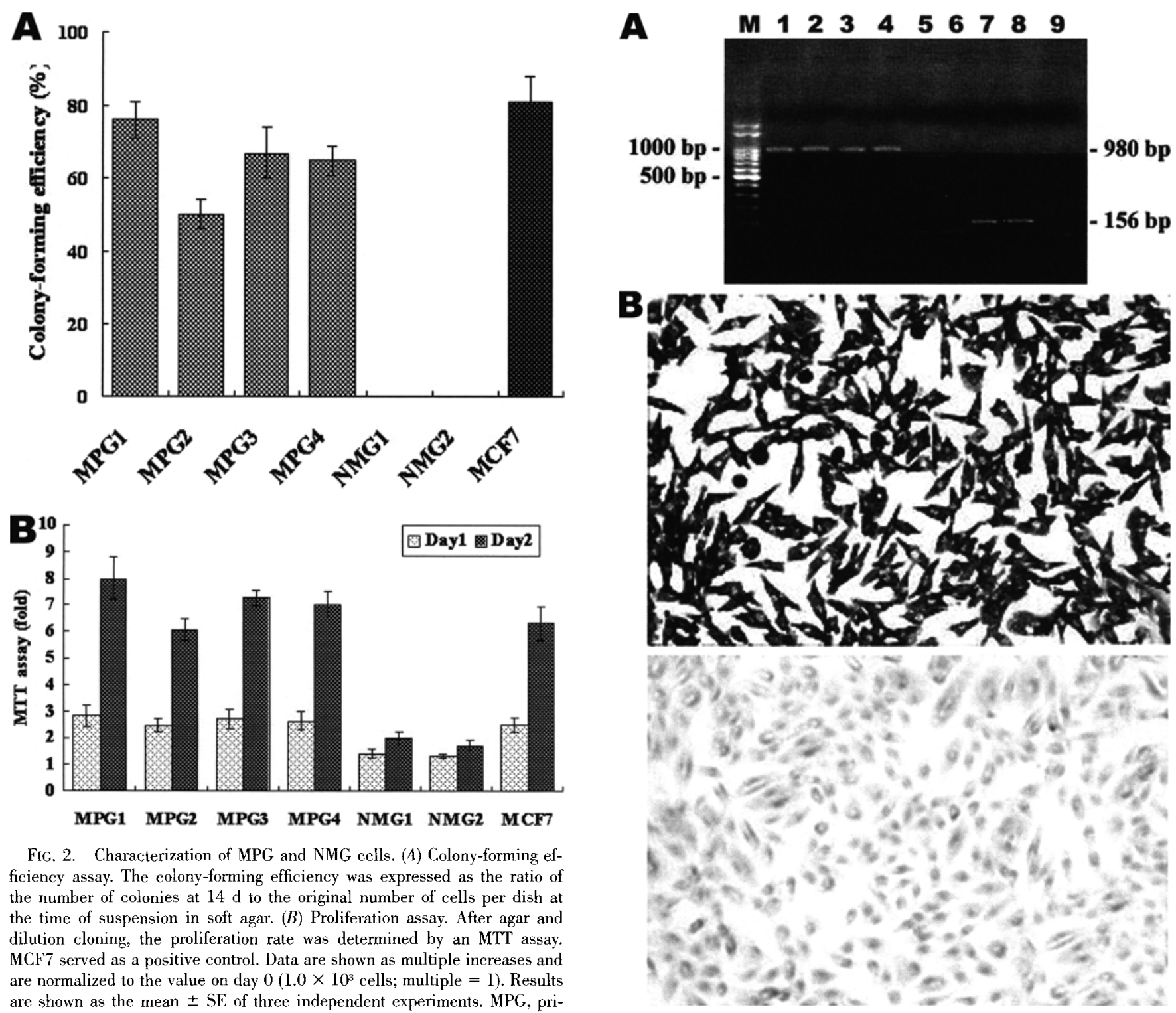

FIG. 2. Characterization of MPG and NMG cells. (A) Colony-forming efficiency assay. The colony-forming efficiency was expressed as the ratio of the number of colonies at $14 \mathrm{~d}$ to the original number of cells per dish at the time of suspension in soft agar. $(B)$ Proliferation assay. After agar and dilution cloning, the proliferation rate was determined by an MTT assay. MCF7 served as a positive control. Data are shown as multiple increases and are normalized to the value on day $0\left(1.0 \times 10^{3}\right.$ cells; multiple $\left.=1\right)$. Results are shown as the mean $\pm \mathrm{SE}$ of three independent experiments. MPG, primary culture from canine mammary tumors; NMG, primary culture from normal canine mammary glands; MTT, 3-(4,5-dimethylthiazole-2-yl)-2,5-biphenyl tetrazolium bromide.

primary cells from CMTs and normal MGs. In our previous studies, we determined that $S F R P 2$ was only expressed in CMT tissues and not in normal MGs. Consistent with tissue screening data, SFRP2 messenger ribonucleic acid (mRNA) was expressed only in primary cultures from CMTs (MPG1-MPG4) and not in primary cultures from normal MGs (NMG1 and NMG2). Furthermore, cells of primary culture from CMTs were also positive for SFRP2 by in situ RNA hybridization (Fig. 3B, upper). The signal was intracytoplasmic. In contrast, cells of primary culture from normal MGs were negative for SFRP2 by in situ RNA hybridization.

Protein analysis of canine SFRP2. All colonies of primary culture and several cell lines (including 293T, HeLa, K562, and P388D1) were screened for SFRP2 by Western blotting. Only cells of primary culture from CMTs (MPG1-MPG4) were positive $(35 \mathrm{kDa})$, and other types of cells were negative (Fig. 4A). Again, MPG1 cells exhibited the highest level of expression. In contrast, MPG2 cells exhib-

FIG. 3. mRNA analysis of SFRP2 expression. (A) Transcripts of canine SFRP2 were analyzed by RT-PCR. Lanes 1-4, MPG1-MPG4; lanes 5 and 6 , NMG1 and NMG2; lanes 7 and 8, RNA integrity was confirmed by monitoring for $\beta$-actin mRNA of NMG1 and NMG2; M, molecular weight marker; lane 9, negative control. The expected sizes of SFRP2 and the $\beta$-actin PCR produets were 980 and $156 \mathrm{bp}$, respectively. $(B)$ In situ hybridization of SFRP2 in MPG1. Cells were hybridized with a digoxigenin-labeled SFRP2 antisense (upper) and sense (bottom) probes. Cells were counterstained with the nuclear stain, hematoxylin. Magnification: $\times 200$. MPG, primary culture from canine mammary tumors; NMG, primary culture from normal canine mammary glands; RNA, ribonucleic acid; mRNA, messenger RNA; RT-PCR, reverse transcriptase-polymerase chain reaction; $\mathrm{PCR}$, polymerse chain reaction; SFRP2, secreted frizzled-related protein 2.

ited the lowest level of expression. In addition, SFRP2 was also detected immunohistochemically in MPG cells (Fig. 4B, upper). Localization of the SFRP2 protein was intracytoplasmic and around cell membranes in MPG cells. In contrast, NMG cells were negative for SFRP2 (Fig. $4 B$, lower).

Western blotting of Wnt signaling-related proteins. To understand the interplay between SFRP2 and Wnt-signaling downstream com- 
A
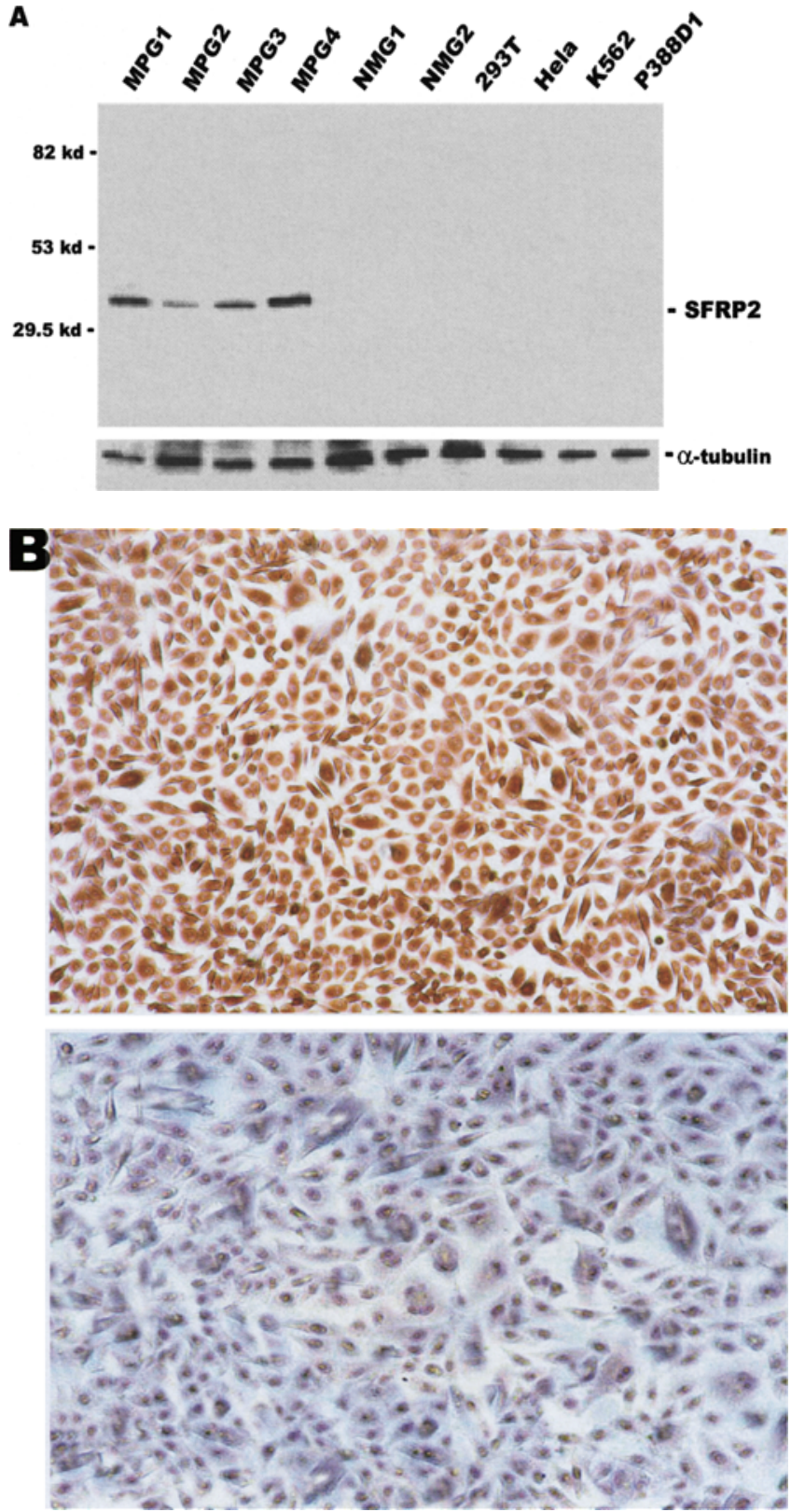

FIG. 4. Protein analysis of SFRP2 expression. (A) Whole-cell extracts were prepared, and $50 \mu \mathrm{g}$ of total protein was separated by SDS-PAGE (I0\%). After membrane transfer, Western analysis was performed with an antibody against SFRP2. For the internal control experiment, a parallel Western analysis was performed on the blots using an antibody to $\alpha$-tubulin. Lanes 1-4, MPG1-MPG4; lanes 5 and 6, NMG1 and NMG2; lane 7, 293T cells; lane 8, HeLa cells; lane 9, K562 cells; lane 10, P388Dl cells. The expected size of the SFRP2 protein was $35 \mathrm{kDa}$. $(B)$ Immunohistochemical detection of SFRP2 in MPG1. Bottom: negative control. Magnification: $\times 100$. MPG, primary culture from canine mammary tumors; NMG, primary culture from normal canine mammary glands; SDS-PAGE, sodium dodecyl sulfate-polyacrylamide gel electrophoresis; SFRP2, secreted frizzled-related protein 2.

ponents, we examined $\beta$-catenin and cyclin D1 expressions in primary culture from normal MGs (NMG1) and CMTs (MPG1 and MPG2 cells exhibited the highest and lowest levels of SFRP2 expression, respectively) by Western blotting (Fig. 5). Secreted frizzled-related protein 2 can be secreted into the culture medium and

\section{NMG1 MPG2 MPG1}

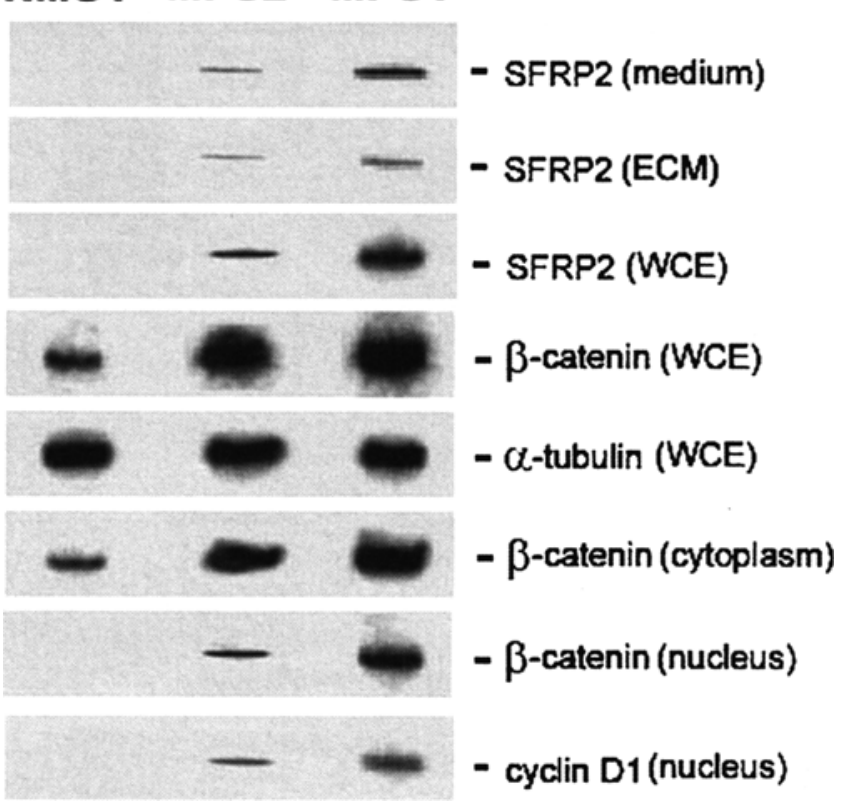

FIG. 5. Increased $\beta$-catenin and cyclin DI in MPG cells expressing secreted frizzled-related protein 2 . Secreted frizzled-related protein 2 levels were examined in whole-cell lysates (T), the extracellular matrix (ECM), and medium from cell culture $(\mathbf{M})$. $\beta$-Catenin levels were analyzed in T, cytoplasmic cell fractions (C), and nuclear cell fractions (N). Cyclin Dl levels were analyzed in N. Control staining was performed with an $\alpha$-tubulin antibody. MPG, primary culture from canine mammary tumors; NMG, primary culture from normal canine mammary glands.

is associated with the ECM. $\beta$-Catenin was detected in both cytoplasmic and nuclear fractions of MPG1 and MPG2 but only in the cytoplasmic fractions of NMG1. Cyclin D1 was present in the nuclear fractions of MPG1 and MPG2. No cyclin D1 was detected in NMG1. Surprisingly, the increased expression of $\beta$-catenin and cyclin D1 in the nuclear fractions was seen in cells overexpressing SFRP2 (MPG1 > MPG2 $\gg$ NMG1). In addition, $\beta$-catenin was translocated into the nucleus in cells expressing SFRP2 (MPG1 and MPG2). In this study, those results were first investigated in a natural (with endogenous expression) system and not in an ectopic overexpressing system.

\section{DisCussion}

Canine mammary tumors in dogs are of special interest to medical and veterinary oncologists because of their close similarities with human breast cancers (Nerurkar et al., 1989). They have similar histologic origins as well as comparable regional, systemic metastases and appearances at similar relative ages (Destexhe et al., 1993). The histological classification of mammary tumors based on World Health Organization guidelines includes the following common tumor types: noninvasive (dogs, in situ carcinoma; humans, ductal and lobular carcinomas in situ); simple carcinoma (dogs, tubulopapillary and solid carcinomas; humans, tubular, papillary, invasive ductal, and lobular carcinomas); and mixed type (dogs, osteosarcoma and carcinosarcoma; humans, cartilaginous and osseous types). The incidence of the various histologic types of tumors differs between the two species (dogs, benign mixed tumor at $45.5 \%$; tubulopapillary carcinoma at $24 \%$; and solid carcinoma at 
$16.9 \%$; and humans, invasive ductal carcinoma at $68.5 \%$ and lobular carcinoma at 7.4\%) (MacEwen and Withrow, 1996; Newcomer et al., 2002). According to Schneider (1970), the incidence of CMTs is three times higher than that of human breast cancers in the same geographical regions of the United States.

The development of mammary tumors in dogs is clearly hormone dependent. The tumor-enhancing effects of ovarian steroids, predominantly those of estrogen and progesterone, are brought about by their mitogenic activity in mammary cells, exerted after binding to their respective receptors. The percentages of positive expression of estrogen receptor $(\mathrm{ER}+)$ and progesterone receptor $(\mathrm{PR}+)$ are 77 and $81 \%$, respectively, in CMTs (Donnay et al., 1995). In comparison, they are 63 and $74 \%$, respectively, in human breast cancers (Middleton et al., 2003). Contrary to the situation in women, ER and PR determinations are not used in the routine prognostication of CMTs, and no additive endocrine therapy is normally given to animals. However, few studies have demonstrated that CMTs have ER and PR profiles and corresponding prognostic implications similar to those of breast cancers (Martin et al., 1984; Donnay et al., 1993).

In this report, we describe a simple method of primary cell culture from CMTs. We used a mechanical technique, instead of enzymatic digestion, to disaggregate the tumor and form a cell suspension. We found that enzymatic digestion was harmful to cells in the initial steps. Tumor cells were further separated from fibroblasts by agar and dilution cloning based on a theory that a single tumor cell can divide into multiple cells, whereas fibroblast cells (normal cells) cannot. After agar and dilution cloning, different cell types in the cell culture represented phenotypic diversity and different stages of differentiation from stem cells. Based on our method, over 90\% of cells exhibited the same phenotype on the basis of morphology and proliferation for up to 70 passages.

The transactivation property of $\beta$-catenin is regulated by the Wnt signaling pathway, which is critical in the development of colorectal cancer and breast cancer (Lin et al., 2000; Polakis, 2000). In addition to its association with Wnt signaling and cell-cell adhesion complexes, $\beta$-catenin also exists as a free pool in the cytosol of cells (Papkoff, 1997). Thus, the dynamic distribution of $\beta$-catenin in different pools may determine its role in different cellular functions. $\beta$-Catenin provides a molecular mechanism for the transmission of signals from cell-cell adhesion components to the nucleus (Polakis, 2000). Consistent with our findings, high nuclear expression ratios of $\beta$-catenin and cyclin D1 were exhibited in both our screening of CMT tissues ( $>70 \%$ positive) and primary culture. We also demonstrated that overexpression of SFRP2 can elevate the $\beta$ catenin expression level in a primary culture model (Lee et al., in prep.). Our data suggest that SFRP2 may play a role in tumorigenesis of CMTs by modulation of Wnt signal-related molecules.

We analyzed the canine SFRP2 gene originally isolated from a subtractive retinal cDNA library. The gene is not expressed in most canine normal adult tissues (Lin and Sargan, 2001). In related stud. ies, several Wnt family members are expressed in normal breast tissues, and some of them are overexpressed in breast cancers and colon cancers (Morin et al., 1997; Bergstein and Brown, 1999; Wong et al., 2002). Wnt-l was initially identified as an oncogene frequently involved in mouse mammary tumors (Tsukamoto et al., 1988; Polakis, 2000; Wong et al., 2002). In an experiment with SFRP2 in CMT tissues in our laboratory, SFRP2 mRNA and protein were expressed only in tissues and primary culture cells from CMTs but not in tissues and primary culture from normal MGs. In previous investigations, well-studied markers of breast carcinoma aggressiveness, such as ERBB2 and P53, were affected in less than $30 \%$ of breast cancers (Ingvarsson, 1999; Ross and Fletcher, 1999; Simpson and Page, 2000). Secreted frizzled-related protein 2 expression was unexpectedly found to be elevated in the vast majority of CMTs (>95\%), suggesting that SFRP2 is one of the most frequent targets of genetic alteration in mammary tumors and may be a candidate tumor marker for CMTs.

Growth of epithelial and endothelial cells is strictly anchorage dependent, with strong cell-matrix and cell-cell contacts (Meredith et al., 1993; Frisch and Francis, 1994; Re et al., 1994). Interactions of cells with the ECM generate and regulate downstream signals that promote cell growth and survival. Elucidating the mechanisms of the interaction of cells with ECM is critical to understanding tumorigenesis and cancer progression. Wnt proteins tend to remain associated with the cell surface or ECM (Bradley and Brown, 1990; Papkoff and Schryver, 1990). Consistent with our findings, we demonstrated that SFRP2 was secreted into the medium and was associated with the ECM. In primary culture cells, the SFRP2 protein could be detected in media collected from stably expressed SFRP2 cells. In addition, the physical interaction of SFRP2 with the fibronectin-integrin protein complex has been demonstrated by coimmunoprecipitation, and cell adhesion could be promoted in the presence of SFRP2. Therefore, SFRP2 is a secreted protein and interacts with fibronectin-integrin receptor protein complexes (Lee et al., in prep.). Secreted frizzled-related protein on ECM and its metabolism may provide further insights into how Wnt signaling can affect tissue restructuring events associated with development and disease pathogenesis (Jones and Jomary, 2002).

Furthermore, we recently found that SFRP2 exhibited antiapoptotic activity in canine and human mammary tumor cell lines (Lee et al., in prep.). Results of our experiments suggest that SFRP2 may play a role in tumorigenesis of mammary tumors. In this study, although it is not clear why SFRP2 is markedly expressed in CMT cells, the presence of SFRP2 may serve as a tumor cell marker for CMTs. More experimentation is required to elucidate the mechanism of the overexpression of SFRP2 in CMTs.

\section{ACKNOWLEDGMENT}

The work was funded by grants (NSC89-2313-B-002-198, NSC 90-2313B-002-294) from the National Science Council, Taiwan, Republic of China.

\section{REFERENCES}

Andreasen, C. B.; Mahaffey, E. A.; Duncan, J. R. Intermediate flament staining in the cytologic and histologic diagnosis of canine skin and soft tissue tumors. Vet. Pathol. 25:343-349; 1998.

Bafico, A.; Gazit, A.; Pramila, T.; Finch, P. W.; Yaniv, A.; Aaronson, S. A. Interaction of Frizzled related protein (FRP) with Wnt ligands and the Frizzled receptor suggests alternative mechanisms for RFP inhibition of Wnt signaling. J. Biol. Chem. 274:16180-16187; 1999.

Bergstein, I.; Brown, A. M. C. Breast eancer. In: Bow-cock, A. M., ed. Molecular genetics, pathogenesis and therapeutics. Totowa, NJ: Human Press; 1999:181-198.

Bradley, R. S.; Brown, A. M. The proto-oncogene int-1 encodes a secreted protein associated with the extracellular matrix. EMBO J. 9:1569-1575; 1990

Chang, C. J.; Chen, Y. L.; Lee, S. C. Coactivator TIF1 interacts with transcription factor C/EBP and gheocorticoid receptor to induce 1-Acid glycoprotein gene expression. Mol. Cell. Biol. 18:5880-5887; 1998. 
Chrisp, C. E.; Spangler, W. L. The malignant canine mammary tumor as a model for the study of human breast cancer. In: Shifrine, M., ed. The canine as a biomedical research model. Washington, DC, US Department of Energy, Technical Information Center; 1980:331-349.

Dendy, P. P. Methodology for human tumor biopsy specimens. In: Dendy, P. P., ed. Human tumors in short term culture. Techniques and clinical applications. Academic Press; Philadelphia, W. B. Saunders; 1976 : $1-64$.

Destexhe, E; Lespagnard, L.; Degeyter, M.; Heymann, R.; Coignoul, F. Immunohistochemical identification of myoepithelial, epithelial, and connective tissue cells in canine mammary tumors. Vet. Pathol. 30:146-154; 1993.

Donnay, I.; Rauis, J.; Devleeschouwer, N.; Wouters-Ballman, P.; Leclercq, G.; Verstegen, J. Comparison of estrogen and progesterone receptor expression in normal and tumor mammary tissues from dogs. Am. J. Vet. Res. 56:1188-1194; 1995.

Donnay, I.; Rauis, J.; Wouters-Ballman, P.; Deuleeschouwer, N.; Leclercq, G.; Verstegen, J. P. Receptors for oestrogen, progesterone and epidermal growth factor in normal and tumorous canine mammary tissues. J. Reprod. Fertil. 47:501-512; 1993.

Finch, P. W.; He, X.; Kelley, M. J., et al. Purification and molecular cloning of a secreted, frizzled-related antagonist of Wnt action. Proc. Natl. Acad. Sci. USA 94:6770-6775; 1997.

Fowler, E. H.; Wilson, G. P.; Koeser, A. Biologic behavior of canine mammary neoplasms based on a histogenic classification. Vet. Pathol. 11:212-229; 1974 .

Frisch, S. M.; Francis, H. Disruption of epithelial cell-matrix interactions induces apoptosis. J. Cell Biol. 124:619-626; 1994.

Fuentealba, I. C.; Mullins, J. E. Immunohistochemical demonstration of metallothionein in benign and malignant eanine mammary tumors. Histol. Histopathol. 14:51-61; 1999.

Grown, A. M.; Vogel, A. M. Monoclonal antibodies to human intermediate filament proteins. Am. J. Clin. Pathol. 84:413-424; 1985.

Hood, C. J.; Parham, D. M. A simple method of tumor culture. Pathol. Res. Pract. 194:177-181; 1998.

Huelsken, J.; Birchmeier, W. New aspects of Wnt signaling pathways in higher vertebrates. Curr. Opin. Genet. Dev. 11:547-553; 2001.

Ingvarsson, S. Molecular genetics of breast cancer progression. Semin. Cancer Biol. 9:277-288; 1999.

Jones, S. E.; Jomary, C. Secreted frizzled-related proteins: searching for relationships and patterns. Bioessays 24:811-820; 2002.

Lin, C. T.; Sargan, D. R. Generation and analysis of canine retinal ESTs: isolation and expression of retina-specific gene transcripts. Biochem. Biophys. Res. Commun. 282:394-403; 2001.

Lin, S. Y.; Xia, W.; Wang, J. C.; Kwong, K. Y.; Spohn, B.; Wen, Y.; Pestell, R. G.; Hung, M. C. $\beta$-Catenin, a novel prognostic marker for breast cancer: its roles in cyclin D1 expression and cancer progression. Proc. Natl. Acad. Sci. USA 97:4262-4266; 2000.

Lin, W. C.; Shen, B. J.; Tsay, Y. G.; Yen, H. C.; Lee, S. C.; Chang, C. J. Transcriptional activation of C/EBPbeta gene by e-Jun and ATF2. DNA Cell Biol. 21:551-560; 2002.

MacEwen, E. G.; Withrow, S. J. Tumors of the mammary gland. In: Withrow, S. J.; Mac:Ewen, E. G., ed. Small animal clinical oncology. Philadelphia, PA: W. B. Saunders; 1996:356-372.

Martin, P. M.; Cotard, M.; Mialot, J. P.; Andre, F.; Raynaud, J. P. Animal models for hormone-dependent human breast cancer. Relationship between steroid receptor profiles in canine and feline mammary tumors and survival rate. Cancer Chemother. Pharmacol. 12:13-17; 1984.
Melkonyan, H. S.; Chang, W. C.; Shapiro, J. P. SARPs: a family of secreted apoptosis-related proteins. Proc. Natl. Acad. Sci. USA 94:13636-13641; 1997.

Meredith, J. E., Jr.; Fazeli, B.; Schwartz, M. A. The extracellular matrix as a cell survival factor. Mol. Biol. Cell 4:953-961; 1993.

Middleton, L. P.; Chen, V.; Perkins, G. H.; Pinn, V.; Page, D. Histopathology of breast cancer among African American women. Cancer 97 (Suppl. 1):253-257; 2003.

Moore, A. S.; Madewell, B. R.; Lund, J. K. Immunohistochemical evaluation of intermediate filament expression in feline neoplasms. Am. J. Vet. Res. 50:88-92; 1989.

Morin, P. J.; Sparks, A. B.; Korinek, V.; Barker, N.; Clevers, H.; Vogelstein, B.; Kinzler, K. W. Activation of $\beta$-catenin-Tcf signaling in colon cancer by mutations in $\beta$-catenin or APC. Science 275:1787-1790; 1997.

Nerurkar, V. R.; Chitale, B. V.; Jalnapurkar, B. V.; Naik, S. N.; Lalitha, V. S. Comparative pathology of canine mammary tumors. J. Comp. Pathol. 101:389-397; 1989.

Newcomer, L. M.; Newcomb, P. A.; Trentham-Dietz, A.; Storer, B. E.; Yasui, Y.; Daling, J. R.; Potter, J. D. Detection method and breast carcinoma histology. Cancer 95:470-477; 2002.

Papkoff, J. Regulation of complexed and free catenin pools by distinct mechanisms. Differential effects of Wnt-1 and v-Src. J. Biol. Chem. 272:4536-4543; 1997.

Papkoff, J.; Schryver, B. Secreted int-1 protein is associated with the cell surface. Mol. Cell. Biol. 10:2723-2730; 1990.

Pierrepoint, C. G. Possible benefits to veterinary medicine of considering the dog as a model for human cancer. J. Small Anim. Pract. 26:43-47; 1985.

Polakis, P. Wnt signaling and cancer. Genes Dev. 14:1837-1851; 2000.

Re, F.; Zanetti, A.; Sironi, M.; Polentarutti, N.; Lanfrancone, L.; Dejana, E.; Colotta, F. Inhibition of anchorage-dependent cell spreading triggers apoptosis in cultured human endothelial cells. J. Cell Biol. $127: 537-546 ; 1994$.

Ross, J. S.; Fletcher, J. A. HER-2/neu (c-erb-B2) gene and protein in breast cancer. Am. J. Clin. Pathol. 112:\$53-S67; 1999.

Schleger, C.; Heck, R.; Niketeghad, F., et al. Establishment and characterization of a non-tumorigenic cell line derived from a human hepatocellular adenoma expressing hepatocyte-specific markers. Exp. Cell Res. 236:418-426; 1997.

Schneider, R. Comparison of age, sex and incidence rates in human and canine breast cancer. Cancer 26:419-426; 1970.

Schumann, H.; Holtz, J.; Zerkowski, H. R.; Hatzfeld, M. Expression of secreted frizzled related protein 3 and 4 in human ventricular myocardium correlates with apoptosis related gene expression. Cardiovasc. Res. 45:720-728; 2000.

Simpson, J. F.; Page, D. L. The p53 tumor suppressor gene in ductal carcinoma in situ of the breast. Am. J. Pathol. 156:5-6; 2000.

Strandberg, J. D.; Goodman, D. G. Animal model of human disease: Breast cancer. Animal model: canine mammary neoplasia. Am. J. Clin. Pathol. 75:225-228; 1974.

Tsukamoto, A. S.; Grosschedl, R.; Guzman, R. C.; Parslow, T.; Varmus, H. E. Expression of the Wnt-1 gene in transgenic mice is associated with mammary gland hyperplasia and adenocarcinomas in male and female mice. Cell 55:619-625; 1988.

Wong, S. C. C.; Lo, S. F. E.; Lee, K. C.; Yam, J. W. P.; Chan, J. K. C.; Hsiao, W. L. W. Expression of frizzled-related protein and Wnt-signaling molecules in invasive human breast tumors. J. Pathol. 196:145-153; 2002 .

Zhou, Z.; Wang, J.; Han, X.; Zhou, J.; Linder, S. Up-regulation of human secreted frizzled homolog in apoptosis and its down-regulation in breast tumors. Int. J. Cancer 78:95-99; 1998. 